\title{
Platelet Reactivity Is Independent of Left Atrial Wall Deformation in Patients with Atrial Fibrillation
}

\author{
Nathan Procter, ${ }^{1}$ Vincent Goh, ${ }^{1}$ Gnanadevan Mahadevan, ${ }^{1}$ \\ Simon Stewart, ${ }^{2}$ and John Horowitz ${ }^{1}$ \\ ${ }^{1}$ Basil Hetzel Institute, The Queen Elizabeth Hospital, The University of Adelaide, Woodville South, SA 5011, Australia \\ ${ }^{2}$ National Health and Medical Research Council Centre of Research Excellence to Reduce Inequality in Heart Disease, \\ Mary MacKillop Institute for Health Research, Australian Catholic University, Melbourne, VIC 3065, Australia
}

Correspondence should be addressed to John Horowitz; john.horowitz@adelaide.edu.au

Received 22 October 2015; Revised 11 February 2016; Accepted 22 February 2016

Academic Editor: Vera L. Petricevich

Copyright (c) 2016 Nathan Procter et al. This is an open access article distributed under the Creative Commons Attribution License, which permits unrestricted use, distribution, and reproduction in any medium, provided the original work is properly cited.

It has been documented recently that left atrial (LA) deformation in AF patients (while in AF) is predictive of subsequent stroke risk. Additionally, diminished LA deformation during AF correlates with the presence of LA blood stasis. Given that endothelial function is dependent on laminar blood flow, the present study sought to investigate the effect of diminished LA deformation (during AF) on platelet reactivity and inflammation in AF patients. Patients $(n=17)$ hospitalised with AF underwent echocardiography (while in AF) for determination of peak positive LA strain (LASp). Whole blood impedance aggregometry was used to measure extent of ADP-induced aggregation and subsequent inhibitory response to the nitric oxide (NO) donor, sodium nitroprusside. Platelet thioredoxin-interacting protein (Txnip) content was determined by immunohistochemistry. LASp tended $(p=0.078)$ to vary inversely with $\mathrm{CHA}_{2} \mathrm{DS}_{2}$ VASc scores. However, mediators of inflammation (C-reactive protein, Txnip) did not correlate significantly with LASp nor did extent of ADP-induced platelet aggregation or platelet NO response. These results suggest that the thrombogenic risk associated with LA stasis is independent of secondary effects on platelet aggregability or inflammation.

\section{Introduction}

Atrial fibrillation (AF) is increasing in global prevalence and carries with it incremental thromboembolic risk. Currently, this risk is assessed through the application of clinical algorithms such as the $\mathrm{CHA}_{2} \mathrm{DS}_{2}$ VASc score [1], from which appropriate antithrombotic therapy may be determined.

The precise pathophysiology underpinning the utility of the $\mathrm{CHA}_{2} \mathrm{DS}_{2} \mathrm{VASc}$ score in predicting thromboembolic events continues to be an ongoing area of investigation: one such facet of this interest is the association of inflammation with thromboembolic risk. Just as inflammation is a pivotal mediator of the pathogenesis of AF [2], it also appears to be involved in thromboembolic risk. Plasma concentrations of the inflammatory mediator Galectin-3 correlated positively [3] and those of the anti-inflammatory mediator adiponectin correlated inversely [4], with $\mathrm{CHA}_{2} \mathrm{DS}_{2}$ VASc scores. The potential utility of these biomarkers in refining the prediction of thromboembolic risk continues to be explored.
An alternative approach to predicting thromboembolic risk relies ultimately on the concept that avoiding stasis of regional wall activity is protective [5]: thus the focus is to investigate the potential of extent of atrial wall motion for predictive power for incidence of thromboembolism. Recently, two-dimensional speckle tracking echocardiography was used to evaluate the extent of left atrial deformation (peak positive left atrial strain, LASp) experienced by patients in AF, correlating diminished LASp with incidence of stroke [6]. Decreased LASp has also been associated with extent of left atrial fibrosis [7], incidence of new onset AF [8], and the occurrence of left atrial blood stasis and thrombus formation [9].

However, it is also possible that the maintenance of left atrial deformation limits rheological stimuli towards thrombosis: nonlaminar blood flow has variously been associated with uncoupling of endothelial nitric oxide (NO) synthase [10], generation of reactive oxygen species [11], and increased expression of the proinflammatory mediator 
thioredoxin-interacting protein (Txnip) [12, 13]. Given the aforementioned propensity for blood stasis in the presence of diminished atrial wall motility and associated risk for thromboembolism, the present study sought to investigate potential intersections of LASp and platelet reactivity, as well as the involvement of the inflammatory mediators C-reactive protein (CRP) and Txnip, in a cohort of AF patients.

\section{Methods}

2.1. Study Population. Patients $(n=17)$ were included as a prospectively defined subset of the Standard versus Atrial Fibrillation Specific Management Study (SAFETY) [14, 15]. Inclusion and exclusion criteria for SAFETY have been reported previously [14]. Patients receiving $\mathrm{P}_{2} \mathrm{Y}_{12}$ receptor antagonist therapy were also excluded due to the impact such agents have on platelet ADP response. All patients underwent transthoracic echocardiography while in AF.

2.2. Clinical. All patients underwent routine clinical and biochemical investigation upon hospital admission. Standard echocardiography including Doppler studies was performed according to established guidelines [16]. Left ventricular ejection fraction was determined using Simpson's biplane method. Measurement of left atrial wall motion was performed as reported by Shih et al. [6], intraobserver coefficient of variation $(\mathrm{CV})$ was $8.3 \%$, and interobserver CV was $5.1 \%$. Mean heart rate during transthoracic echocardiography was $84 \pm 12 \mathrm{bpm}$.

2.3. Laboratory. Platelet aggregometry was performed using whole blood impedance aggregometry as previously described [17]. Briefly, venous blood was collected from an antecubital vein into $10 \mathrm{~mL}$ tubes containing 1:10 volume of acid citrate anticoagulant ( 2 parts of $0.1 \mathrm{M}$ citric acid to 3 parts of $0.1 \mathrm{M}$ trisodium citrate). Aggregation was induced with ADP $(2.5 \mu \mathrm{M})$, and responses were recorded for electrical impedance $(\Omega)$ via a computer interface system (Aggrolink, Chrono-Log, Havertown, Pennsylvania, USA). The NO donor sodium nitroprusside (SNP, $10 \mu \mathrm{M}$ ) was used to measure platelet response to NO. Inhibition of aggregation by SNP was evaluated as percentage of maximal aggregation in the absence of SNP. In order to minimize inaccuracies in calculation of inhibitory effect of SNP, at least $4 \Omega$ of ADP response was required.

2.4. Statistical Methods. All data for normally distributed parameters are expressed as mean \pm standard deviation unless otherwise stated. Skewed data are expressed as median and interquartile range (IQR). Where applicable, nonnormal distributions were transformed using Log or Ln functions. Univariate correlates of LASp were sought by linear regression. Data were analyzed using the IBM SPSS Statistics 20 and GraphPad Prism 6 software packages.

\section{Results}

The clinical and pharmacological profiles of the study cohort can be observed in Tables 1 and 2, respectively. A total of
TABLE 1: Clinical profile of the study cohort.

\begin{tabular}{lc}
\hline Sociodemographic profile $(n=17)$ & \\
Gender, $n$ (\% male) & $9(52.9)$ \\
Age $(\mathrm{yrs})$ & $72 \pm 12$ \\
$\quad$ Aged $\geq 75$ years, $n(\%)$ & $9(52.9)$ \\
Comorbidities & $2(11.8)$ \\
Congestive heart failure, $n(\%)$ & $11(64.7)$ \\
Hypertension, $n(\%)$ & $4(23.5)$ \\
Diabetes mellitus, $n(\%)$ & $4(23.5)$ \\
Prior stroke/TIA, $n(\%)$ & \\
Clinical presentation & $98 \pm 31$ \\
Admission heart rate $(\mathrm{bpm})$ & $86 \pm 22$ \\
Plasma creatinine $(\mu \mathrm{M})$ & $16.0 \pm 23.3$ \\
Plasma CRP $(\mathrm{mg} / \mathrm{L})^{\mathrm{CHA}_{2} \mathrm{DS}_{2} \text { VASc score }}$ & $3.1 \pm 2.0$ \\
\hline
\end{tabular}

TABLE 2: Pharmacological therapy present in the study cohort.

\begin{tabular}{lr}
\hline \multicolumn{2}{c}{ Pharmacological profile $(n=17)$} \\
\hline Antithrombotic therapy \\
$\quad$ Aspirin, $n(\%)$ & $4(23.5)$ \\
Warfarin, $n(\%)$ & $13(76.5)$ \\
Rate and/or rhythm control therapy & $5(29.4)$ \\
$\quad$ Antiarrhythmics, $n(\%)$ & $11(64.7)$ \\
$\quad \beta$ receptor antagonist, $n(\%)$ & \\
RAAS inhibitors & $9(52.9)$ \\
$\quad$ ACE inhibitor, $n(\%)$ & $5(29.4)$ \\
$\quad$ Angiotensin receptor antagonist, $n(\%)$ & \\
Other medications & $6(35.3)$ \\
$\quad$ Statin, $n(\%)$ &
\end{tabular}

TABLE 3: Echocardiographic profile of the study cohort.

\begin{tabular}{lc}
\hline Echocardiographic profile $(n=17)$ & \\
Indexed left atrial volume $\left(\mathrm{mm} \cdot \mathrm{m}^{-2}\right)$ & $39.7 \pm 13.0$ \\
Left atrial emptying fraction $(\%)$ & $21.9 \pm 11.0$ \\
Peak positive left atrial strain $(\%)$ & $10.6 \pm 2.4$ \\
Left ventricular emptying fraction $(\%)$ & $53.7 \pm 7.3$ \\
\hline
\end{tabular}

8 patients were excluded from analysis because of inadequate quality of LASp determination from echocardiographic records. Patients were typical for an AF population, being elderly, of moderate stroke risk on the basis of clinical scoring algorithms, and with relatively preserved renal function. The majority of patients were receiving oral anticoagulant (warfarin) therapy and renin-angiotensin-aldosterone system blockade (angiotensin receptor antagonists or angiotensinconverting enzyme antagonists), while approximately $1 / 3$ were on lipid-lowering therapies (statins). Echocardiographic parameters of interest are summarised in Table 3.

The extent of atrial wall motility during AF bore no significant relationship with platelet reactivity (Figure 1): correlations between LASp and ADP-induced platelet aggregation, or LASp and platelet response to NO, were both nonsignificant. It should be noted, indeed, that if anything, 


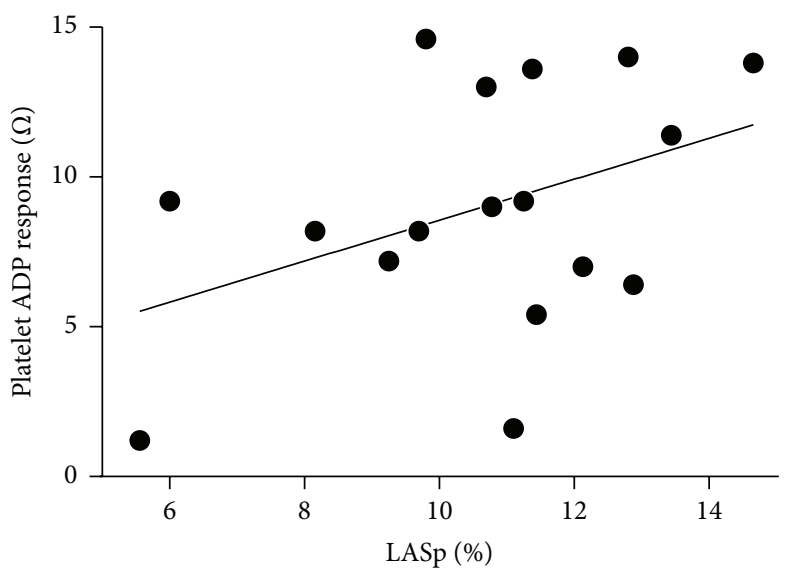

(a)

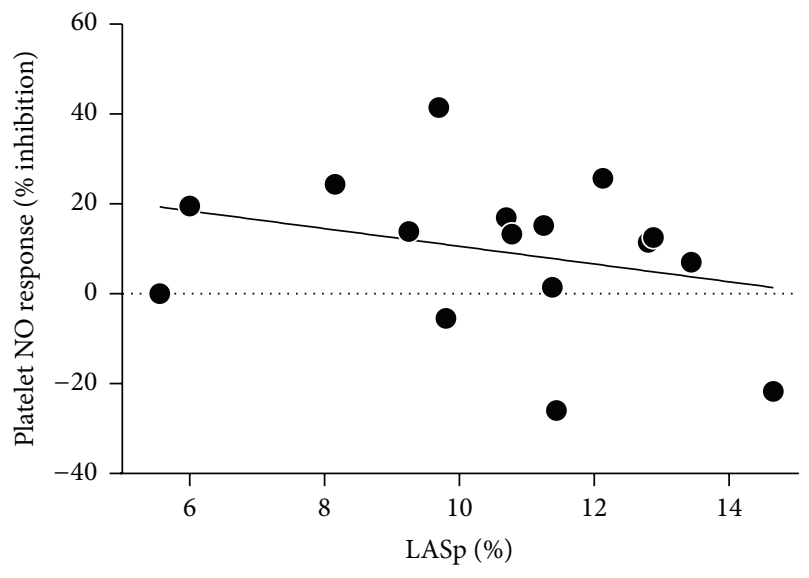

(b)

FIGURE 1: Relationships between peak positive left atrial strain (LASp) and (a) ADP-induced platelet aggregation $(r=0.408, p=0.104)$ or (b) platelet response to $\mathrm{NO}(r=-0.290, p=0.275)$.

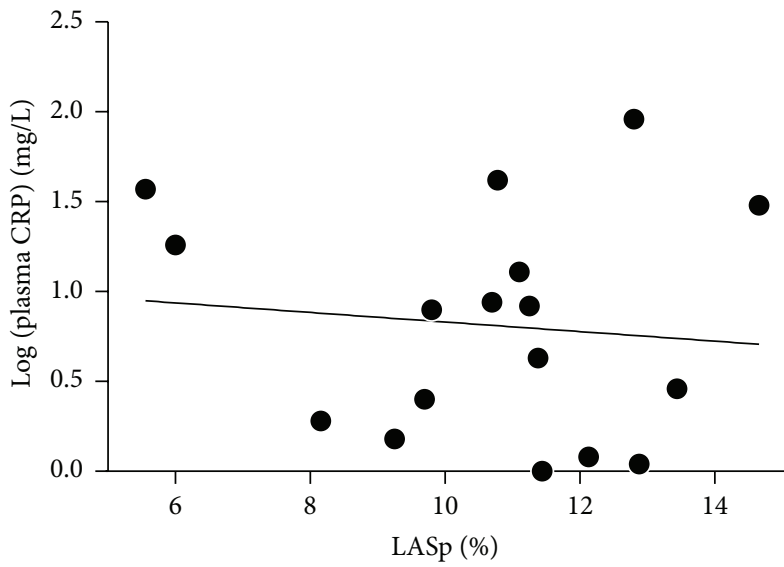

(a)

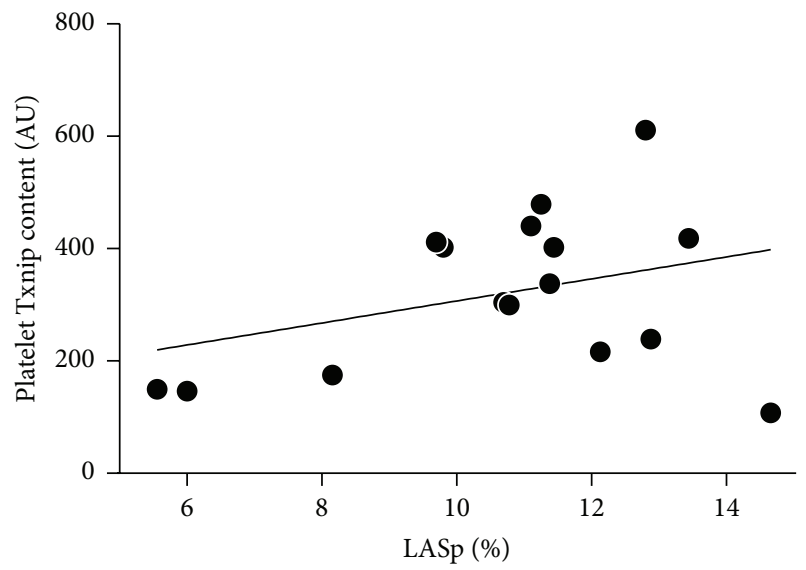

(b)

FIGURE 2: No significant correlation was observed between LASp and (a) plasma CRP concentrations $(r=-0.105, p=0.689)$ or $(\mathrm{b})$ platelet Txnip content $(r=0.345, p=0.191)$.

there was an association ( $p=0.104)$ between increasing LASp and increasing ADP-induced platelet aggregation. Similarly, LASp was not significantly associated with plasma CRP concentrations nor with platelet Txnip content (Figure 2). A trend towards an inverse association between CHA2DS2VASc scores and LASp was observed, while CHA2DS2VASc scores and indexed LA volume were directly correlated (Figure 3).

\section{Discussion}

The current study, unique in the literature to date, has suggested that LASp may vary inversely with clinical indices of stroke risk, such as $\mathrm{CHA}_{2} \mathrm{DS}_{2}$ VASc score. However, it has failed to demonstrate any evidence that maintained LASp might protect against thromboembolism by restoring homeostasis as regards the inflammatory and autacoid bases for thrombosis.
Patients with AF are particularly susceptible to the development of thrombi in their left atrium, with the presence of left atrial blood stasis, a significant factor in their formation $[18,19]$. Similarly, left atrial stasis has been correlated with clinical risk factors and stroke incidence $[5,20]$. Such thrombi are commonly platelet-rich in their morphology [21]; while not correlated with clinical measures of thromboembolic risk $[22,23]$, the platelet hyperaggregability that is present in patients with AF $[24,25]$ nonetheless would seemingly have an integral role in the formation of such thrombi.

One of the factors contributing to platelet hyperaggregability in this context is potential impairment of the NO signaling pathway (see [26] for review). Effective generation of NO by endothelial NO synthase is impaired by the presence of nonlaminar blood flow, such as what occurs in the presence of $\mathrm{AF}[11,27,28]$. In theory, the extent of atrial motility present during AF may help preserve the functioning of this pathway through amelioration of blood stasis and, as such, would be 


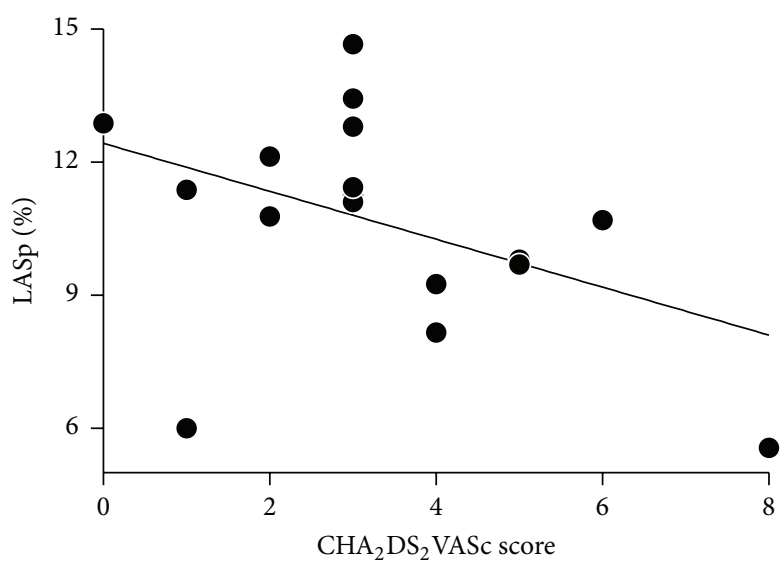

(a)

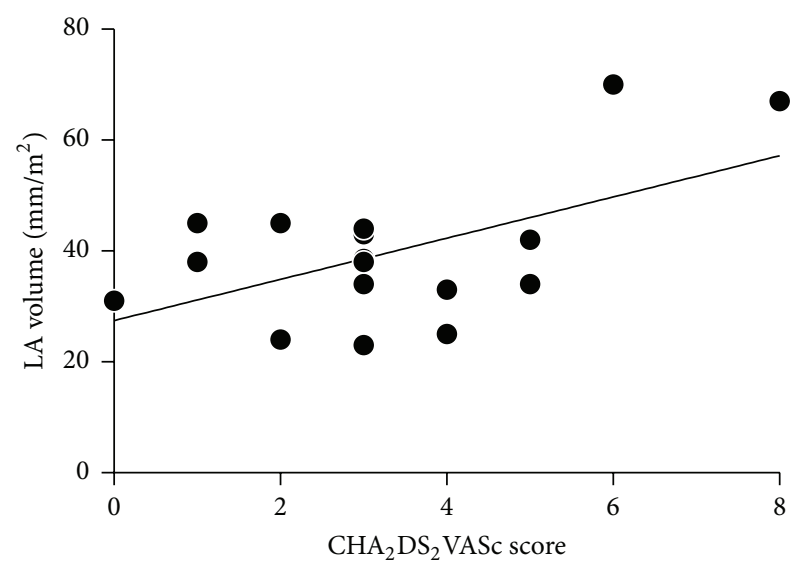

(b)

Figure 3: (a), An inverse trend between LASp and $\mathrm{CHA}_{2} \mathrm{DS}_{2}$ VASc score was nonsignificant $(r=-0.44, p=0.08)$. (b) $\mathrm{CHA}_{2} \mathrm{DS}_{2} \mathrm{VASc}_{\mathrm{Score}}$ and indexed LA volume were directly correlated $(r=0.56, p<0.05)$.

reflected through measures of platelet reactivity. However, in our investigation we observed no such correlation between atrial wall movement and platelet response to ADP or NO. Similarly, inflammation is regulated in part by NO $[29,30]$; specifically Txnip expression is suppressed by the presence of NO [31, 32]. Yet no correlation was observed between atrial wall motion and markers of inflammation in the current investigation.

One potential cause for error in acquisition of LASp data is variable degrees of tachycardia in the LA [6]. This problem was minimized because the actual heart rate during LASp measurement was $84 \pm 12$ beats per minute (bpm) and because multiple views of the LA were incorporated. Reproducibility of LA strain estimates in AF patients is best achieved by considering only periods of relative heart rate stability [33]. No particular precautions were taken in this regard, and this therefore constitutes a potential limitation on accuracy of data.

The major limitation of the current study is the potential for type 2 error. However, it seems unlikely from the current data that any strong correlation has been missed, as regards the measured physiological parameters. However, it is possible that platelet responsiveness to NO may not reflect that of the endocardial endothelium.

According to the principles outlined by Virchow's triad [34], the presence of blood stasis in the atria during AF is a predisposing factor for thrombogenesis. The current data dissociate this stasis from increased platelet reactivity and/or inflammation. Given that biomechanical (such as LASp), as opposed to biochemical, factors are the primary determinants of left atrial thrombogenesis, it would be expected that effective maintenance of sinus rhythm in AF patients would significantly reduce their thromboembolic risk through improved atrial flow.

\section{Competing Interests}

The authors declare that they have no competing interests.

\section{Acknowledgments}

This investigation was supported by an NHMRC Program Grant and the NHMRC Centre of Research Excellence to Reduce Inequality in Heart Disease. Simon Stewart is supported by the NHMRC. Nathan Procter is supported by The University of Adelaide.

\section{References}

[1] G. Y. H. Lip, R. Nieuwlaat, R. Pisters, D. A. Lane, and H. J. G. M. Crijns, "Refining clinical risk stratification for predicting stroke and thromboembolism in atrial fibrillation using a novel risk factor-based approach: the Euro Heart Survey on atrial fibrillation," Chest, vol. 137, no. 2, pp. 263-272, 2010.

[2] V. Rudolph, R. P. Andrié, T. K. Rudolph et al., "Myeloperoxidase acts as a profibrotic mediator of atrial fibrillation," Nature Medicine, vol. 16, no. 4, pp. 470-474, 2010.

[3] D. T. Martin, M. M. Bersohn, A. L. Waldo et al., "Randomized trial of atrial arrhythmia monitoring to guide anticoagulation in patients with implanted defibrillator and cardiac resynchronization devices," European Heart Journal, vol. 36, no. 26, pp. 1660-1668, 2015.

[4] M. P. Turakhia, P. D. Ziegler, S. K. Schmitt et al., "Atrial fibrillation burden and short-term risk of stroke: case-crossover analysis of continuously recorded heart rhythm from cardiac electronic implanted devices," Circulation: Arrhythmia and Electrophysiology, vol. 8, no. 5, pp. 1040-1047, 2015.

[5] B. K. Shively, E. A. Gelgand, and M. H. Crawford, "Regional left atrial stasis during atrial fibrillation and flutter: determinants and relation to stroke," Journal of the American College of Cardiology, vol. 27, no. 7, pp. 1722-1729, 1996.

[6] J.-Y. Shih, W.-C. Tsai, Y.-Y. Huang et al., "Association of decreased left atrial strain and strain rate with stroke in chronic atrial fibrillation," Journal of the American Society of Echocardiography, vol. 24, no. 5, pp. 513-519, 2011.

[7] M. Cameli, M. Lisi, F. M. Righini et al., "Usefulness of atrial deformation analysis to predict left atrial fibrosis and endocardial thickness in patients undergoing mitral valve operations for 
severe mitral regurgitation secondary to mitral valve prolapse," American Journal of Cardiology, vol. 111, no. 4, pp. 595-601, 2013.

[8] T. Hirose, M. Kawasaki, R. Tanaka et al., "Left atrial function assessed by speckle tracking echocardiography as a predictor of new-onset non-valvular atrial fibrillation: results from a prospective study in 580 adults," European Heart Journal Cardiovascular Imaging, vol. 13, no. 3, pp. 243-250, 2012.

[9] R. Providência, A. Faustino, M. J. Ferreira et al., "Evaluation of left atrial deformation to predict left atrial stasis in patients with non-valvular atrial fibrillation-a pilot-study," Cardiovascular Ultrasound, vol. 11, article 44, 2013.

[10] H. Cai, Z. Li, A. Goette et al., "Downregulation of endocardial nitric oxide synthase expression and nitric oxide production in atrial fibrillation: potential mechanisms for atrial thrombosis and stroke," Circulation, vol. 106, no. 22, pp. 2854-2858, 2002.

[11] K.-S. Heo, K. Fujiwara, and J.-I. Abe, "Disturbed-flow-mediated vascular reactive oxygen species induce endothelial dysfunction," Circulation Journal, vol. 75, no. 12, pp. 2722-2730, 2011.

[12] X.-Q. Wang, P. Nigro, C. World, K. Fujiwara, C. Yan, and B. C. Berk, "Thioredoxin interacting protein promotes endothelial cell inflammation in response to disturbed flow by increasing leukocyte adhesion and repressing Kruppel-like factor 2," Circulation Research, vol. 110, no. 4, pp. 560-568, 2012.

[13] H. Yamawaki, S. Pan, R. T. Lee, and B. C. Berk, "Fluid shear stress inhibits vascular inflammation by decreasing thioredoxin-interacting protein in endothelial cells," The Journal of Clinical Investigation, vol. 115, no. 3, pp. 733-738, 2005.

[14] M. J. Carrington, J. Ball, J. D. Horowitz et al., "Navigating the fine line between benefit and risk in chronic atrial fibrillation: rationale and design of the Standard versus Atrial Fibrillation spEcific managemenT studY (SAFETY)," International Journal of Cardiology, vol. 166, no. 2, pp. 359-365, 2013.

[15] S. Stewart, J. Ball, J. D. Horowitz et al., "Standard versus atrial fibrillation-specific management strategy (SAFETY) to reduce recurrent admission and prolong survival: pragmatic, multicentre, randomised controlled trial," The Lancet, vol. 385, no. 9970, pp. 775-784, 2015.

[16] R. M. Lang, M. Bierig, R. B. Devereux et al., "Recommendations for chamber quantification: a report from the American Society of Echocardiography's guidelines and standards committee and the Chamber Quantification Writing Group, developed in conjunction with the European Association of Echocardiography, a branch of the European Society of Cardiology," Journal of the American Society of Echocardiography, vol. 18, no. 12, pp. 14401463, 2005.

[17] S. R. Willoughby, S. Rajendran, W. P. Chan et al., "Ramipril sensitizes platelets to nitric oxide: implications for therapy in highrisk patients," Journal of the American College of Cardiology, vol. 60, no. 10, pp. 887-894, 2012.

[18] W. J. Manning, D. I. Silverman, C. A. Waksmonski, P. Oettgen, and P. S. Douglas, "Prevalence of residual left atrial thrombi among patients with acute thromboembolism and newly recognized atrial fibrillation," Archives of Internal Medicine, vol. 155, no. 20, pp. 2193-2198, 1995.

[19] D. N. Rubin, S. E. Katz, M. F. Riley, P. S. Douglas, and W. J. Manning, "Evaluation of left atrial appendage anatomy and function in recent-onset atrial fibrillation by transesophageal echocardiography," The American Journal of Cardiology, vol. 78, no. 7, pp. 774-778, 1996.

[20] K. Ohara, T. Hirai, N. Fukuda et al., "Relation of left atrial blood stasis to clinical risk factors in atrial fibrillation," International Journal of Cardiology, vol. 132, no. 2, pp. 210-215, 2009.
[21] W. E. Wysokinski, S. G. Owen, D. N. Fass, D. D. Patrzalek, L. Murphy, and R. D. McBane II, "Atrial fibrillation and thrombosis: immunohistochemical differences between in situ and embolized thrombi," Journal of Thrombosis and Haemostasis, vol. 2, no. 9, pp. 1637-1644, 2004.

[22] D. S. G. Conway, J. Heeringa, D. A. M. Van Der Kuip et al., "Atrial fibrillation and the prothrombotic state in the elderly: the Rotterdam Study," Stroke, vol. 34, no. 2, pp. 413-417, 2003.

[23] M. Hammwöhner, A. Ittenson, J. Dierkes et al., "Platelet expression of CD40/CD40 ligand and its relation to inflammatory markers and adhesion molecules in patients with atrial fibrillation," Experimental Biology and Medicine, vol. 232, no. 4, pp. 581-589, 2007.

[24] S. Kamath, A. D. Blann, B. S. P. Chin et al., "A study of platelet activation in atrial fibrillation and the effects of antithrombotic therapy," European Heart Journal, vol. 23, no. 22, pp. 1788-1795, 2002.

[25] K. Ohara, H. Inoue, T. Nozawa et al., "Accumulation of risk factors enhances the prothrombotic state in atrial fibrillation," International Journal of Cardiology, vol. 126, no. 3, pp. 316-321, 2008.

[26] N. E. Procter, C. Chong, A. Sverdlov, W. Chan, Y. Chirkov, and J. Horowitz, "Aging of platelet nitric oxide signaling: pathogenesis, clinical implications, and therapeutics," Seminars in Thrombosis and Hemostasis, vol. 40, no. 6, pp. 660-668, 2014.

[27] N. Takahashi, Y. Ishibashi, T. Shimada et al., "Atrial fibrillation impairs endothelial function of forearm vessels in humans," Journal of Cardiac Failure, vol. 7, no. 1, pp. 45-54, 2001.

[28] S. Yoshino, A. Yoshikawa, S. Hamasaki et al., "Atrial fibrillationinduced endothelial dysfunction improves after restoration of sinus rhythm," International Journal of Cardiology, vol. 168, no. 2, pp. 1280-1285, 2013.

[29] U. Förstermann, "Nitric oxide and oxidative stress in vascular disease," Pflugers Archiv European Journal of Physiology, vol. 459, no. 6, pp. 923-939, 2010.

[30] L. P. van der Zwan, P. G. Scheffer, J. M. Dekker, C. D. A. Stehouwer, R. J. Heine, and T. Teerlink, "Systemic inflammation is linked to low arginine and high ADMA plasma levels resulting in an unfavourable nos substrate-to-inhibitor ratio: the Hoorn Study," Clinical Science, vol. 121, no. 2, pp. 71-78, 2011.

[31] P. C. Schulze, H. Liu, E. Choe et al., "Nitric oxide-dependent suppression of thioredoxin-interacting protein expression enhances thioredoxin activity," Arteriosclerosis, Thrombosis, and Vascular Biology, vol. 26, no. 12, pp. 2666-2672, 2006.

[32] A. L. Sverdlov, W. P. A. Chan, N. E. K. Procter, Y. Y. Chirkov, D. T. M. Ngo, and J. D. Horowitz, "Reciprocal regulation of NO signaling and TXNIP expression in humans: impact of aging and ramipril therapy," International Journal of Cardiology, vol. 168, no. 5, pp. 4624-4630, 2013.

[33] S. Sasaki, T. Watanabe, H. Tamura et al., "Left atrial strain as evaluated by two-dimensional speckle tracking predicts left atrial appendage dysfunction in patients with acute ischemic stroke," BBA Clinical, vol. 2, pp. 40-47, 2014.

[34] G. D. O. Lowe, "Virchow's triad revisited: abnormal flow," Pathophysiology of Haemostasis and Thrombosis, vol. 33, no. 5-6, pp. 455-457, 2003. 


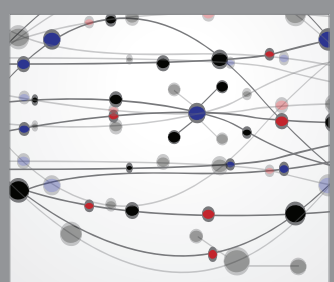

The Scientific World Journal
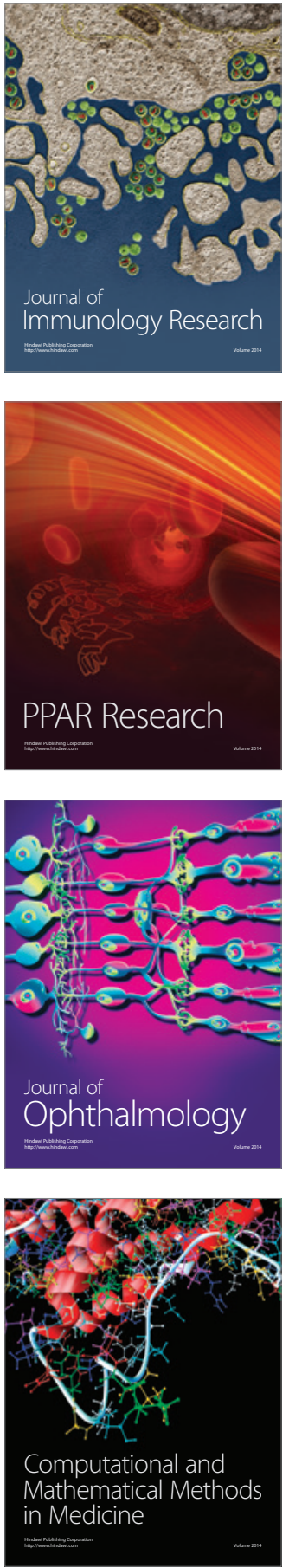

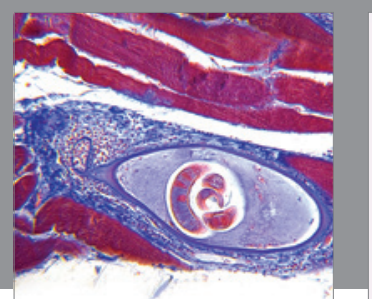

Gastroenterology Research and Practice

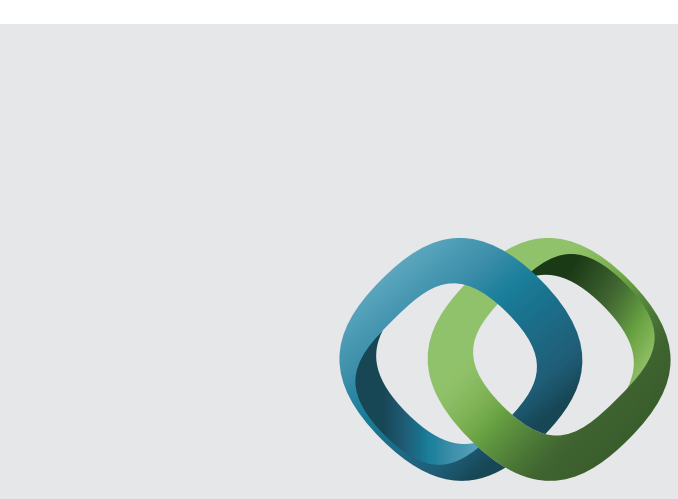

\section{Hindawi}

Submit your manuscripts at

http://www.hindawi.com
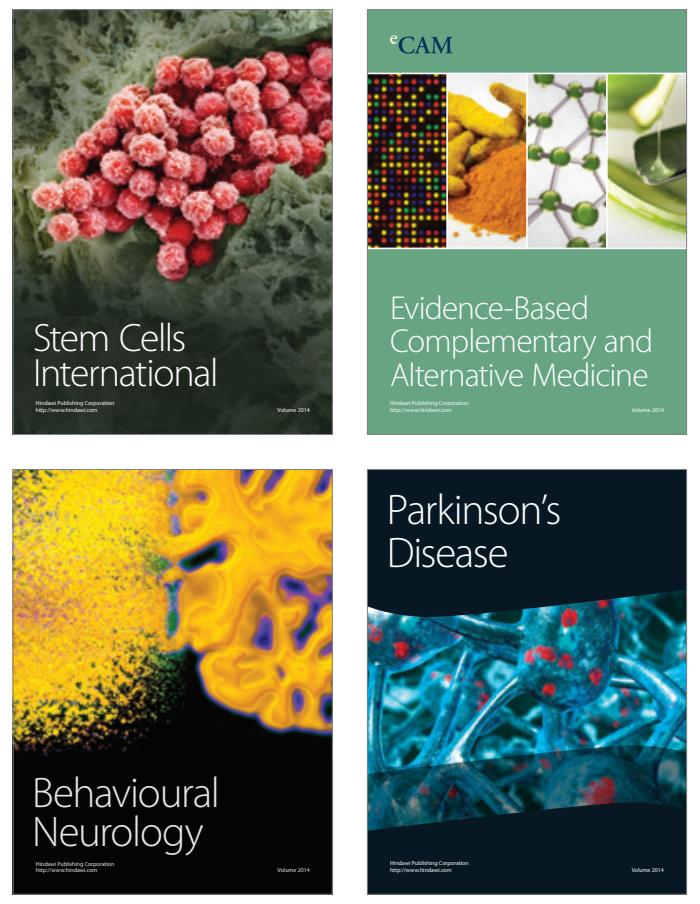
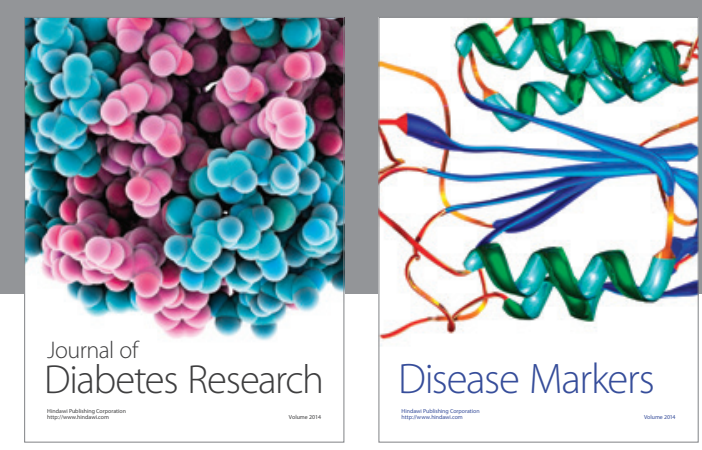

Disease Markers
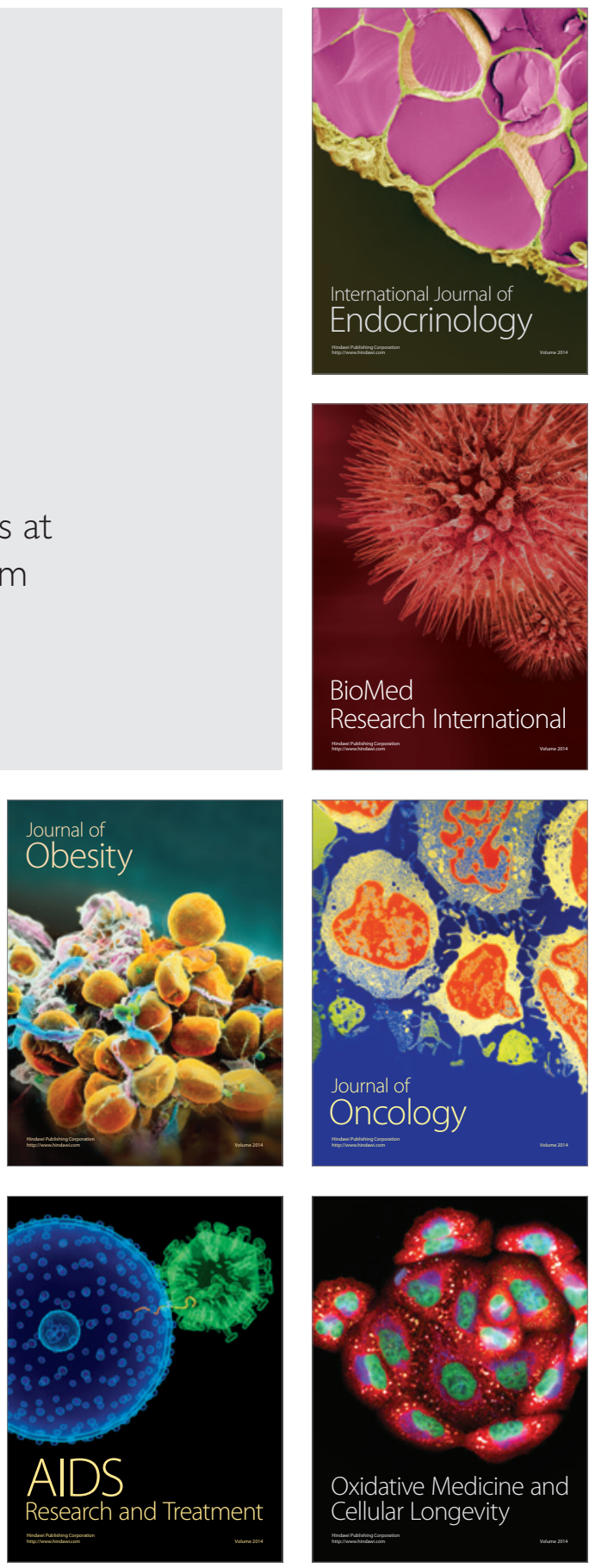